\title{
A Experiência de Aposentadoria em Profissionais Autônomos: Um Estudo Fenomenológico
}

\author{
Ana Paula Couto Zoltowski* \& Marco Antônio Pereira Teixeira \\ Universidade Federal do Rio Grande do Sul, Porto Alegre, Brasil
}

\begin{abstract}
RESUMO
O objetivo deste estudo foi descrever qualitativamente a experiência de aposentadoria em profissionais autônomos. Foram entrevistados dez trabalhadores autônomos aposentados, com idades entre 60 e 91 anos. As entrevistas foram analisadas seguindo uma abordagem fenomenológica empírica. Para os autônomos, a aposentadoria basicamente significa o recebimento de um benefício social. Verificou-se que existe um desejo de continuar trabalhando até a imposição de limites do corpo e da mente para a saída total do mercado de trabalho. Conclui-se que a aposentadoria para os autônomos promove uma transformação do papel de trabalhador ao longo do tempo, modificando a dinâmica de outros papéis desempenhados pelo sujeito.
\end{abstract}

Palavras-chave: aposentadoria; profissional autônomo; aposentadoria em autônomos; envelhecimento; fenomenologia.

\begin{abstract}
The retirement experience of self-employed professionals: a phenomenological study

The aim of this study was to qualitatively describe the retirement experience of self-employed professionals. Ten retirees who worked as self-employed workers, aged between 60 and 91 years, were interviewed. The interviews were analyzed employing an empirical phenomenological approach. For the self-employed professionals, retirement basically means receiving a social benefit. There is a desire to keep working while the body and the mind still allow the development of professional activities before quitting work totally. In conclusion, retirement among self-employed people promotes a transformation in the work role through time, changing the dynamics of other social roles enacted by the subject.
\end{abstract}

Keywords: retirement; self-employed worker; self-employed retirement; aging; phenomenology.

A aposentadoria é um fenômeno social relativamente novo. Apenas entre os anos de 1900 e 1950, com a estruturação da seguridade social em diversos países e o surgimento das pensões privadas, a aposentadoria passou a ser reconhecida como uma possibilidade legítima na vida das pessoas (Schultz \& Wang, 2011). De um ponto de vista formal e objetivo, caracteriza-se pelo recebimento de algum tipo de benefício social proveniente do tempo de contribuição recolhido, usualmente associado a um afastamento total ou parcial do trabalho. Além do aspecto financeiro, podese compreender a aposentadoria como um processo de carreira localizado temporalmente e que envolve dife- rentes papéis de vida do sujeito (Super, Savickas, \& Super, 1996). A abordagem life-span, life-space de desenvolvimento de carreira indica que a trajetória de vida é marcada por tarefas sociais esperadas que situam a história do sujeito ao longo do tempo (dimensão lifespan), ao mesmo tempo em que ressalta a importância da interação dos papéis que são desempenhados pelo indivíduo nos seus diferentes contextos de vida (dimensão life-space) (Savickas, 2002). Segundo esta abordagem, a aposentadoria pode ser entendida como uma transição de carreira a ser cumprida pelo trabalhador quando este chega ao estágio de carreira de desengajamento, que inclui também as tarefas de de-

\footnotetext{
*Endereço para correspondência: Ana Paula Couto Zoltowski - ana_zoltowski@yahoo.com.br
} 
saceleração do mundo do trabalho e de transposição dos interesses laborais em outros tipos de interesses (Super et al., 1996).

Os estudos sobre aposentadoria tendem a focar tipicamente trabalhadores assalariados, seja do setor público, seja do setor privado, não sendo dada muita atenção a possíveis especificidades de carreira de profissionais autônomos (DeVaney \& Kim, 2003). Dentre as várias definições possíveis, o profissional autônomo pode ser visto como aquele que exerce por conta própria atividade profissional remunerada por serviços prestados (Mourão \& Pantoja, 2010). Todavia, não há um consenso acerca de quais critérios devem ser adotados para definir o trabalhador autônomo (Le, 1999). Dessa forma, a tendência presente em pesquisas nesta área é a utilização de um critério via autorrelato, no qual o indivíduo reconhece-se como profissional autônomo (Earle \& Sakova, 2000).

Quinn (1980) já apontava as diferenças entre trabalhadores autônomos e trabalhadores assalariados no que se refere à forma de encararem a aposentadoria. Por possuírem um ambiente de trabalho geralmente caracterizado pela flexibilidade de horas trabalhadas e pela ausência de uma aposentadoria compulsória, os autônomos tornam-se menos propensos a se aposentarem (sendo a aposentadoria aqui identificada como a saída do mercado de trabalho). Autônomos tendem a pensar menos na aposentadoria e demonstram mais incerteza sobre a possibilidade de se aposentar (Ekerdt, Kosloski, \& Deviney, 2000). Nesse sentido, ressalta-se também que tanto homens quanto mulheres profissionais liberais apresentam maior desejo de permanecer trabalhando após os 65 anos de idade, se comparados com homens e mulheres assalariados (Soidre, 2005).

Em uma pesquisa que investigou expectativas de trabalhadores australianos de meia-idade sobre a aposentadoria, Cobb-Clark e Stillman (2009) verificaram que autônomos eram mais propensos a relatarem indecisão sobre a idade em que planejavam se aposentar, quando comparados aos assalariados. Segundo os autores, a antecipação de quando deixar o mercado de trabalho parece ser mais fácil para trabalhadores cujos empregos são mais bem definidos nos quesitos rendimentos, benefícios e idades-limite para a aposentadoria. Como profissionais autônomos geralmente não possuem ambientes de trabalho tão bem delineados e circunscritos socialmente, a decisão sobre o momento de saída do mercado de trabalho torna-se menos previsível. Possuir um ambiente de trabalho mais estruturado, principalmente quanto à rotina de trabalho, pa- rece facilitar o planejamento para a aposentadoria (Ekerdt, Hackney, Kosloski, \& DeViney, 2001). Além disso, o recebimento do benefício pode ser visto como um preditor importante para a tomada de decisão sobre a aposentadoria, principalmente por caracterizarse como um referencial socialmente institucionalizado (Cobb-Clark \& Stillman, 2009). Sem o benefício, pode não haver um marcador a partir do qual se pensar concretamente sobre a aposentadoria.

Vivendo em um ambiente de trabalho menos definido e estruturado socialmente, diversos fatores motivam os profissionais autônomos a decidirem por seguir trabalhando após a idade de aposentadoria. Parry e Taylor (2007) afirmam que profissionais liberais tendem a expressar forte desejo de independência e autossuficiência. Outra pesquisa também indicou que profissionais autônomos mais velhos, que tinham o trabalho como aspecto central da vida e que se sentiam recompensados por dirigirem o próprio negócio eram mais propensos a continuarem trabalhando, mesmo com a proximidade da aposentadoria (Templer, Armstrong-Stassen, \& Cataneo, 2010). É possível perceber que, ao ocupar um papel central, o trabalho para os autônomos torna-se característica essencial do seu autoconceito, ou seja, a imagem que o indivíduo possui de si mesmo (Super et al., 1996).

Quanto ao significado e impacto da aposentadoria, é possível identificar mais diferenças entre assalariados e autônomos. No estudo de Parry e Taylor (2007), os assalariados perceberam a aposentadoria como uma espécie de recompensa por um trabalho visto como estressante e insatisfatório, sendo indicativo de um período de liberdade e autonomia, algo antes não vivido nas suas ocupações. Por outro lado, os autônomos avaliaram que sua trajetória não seria modificada totalmente pela presença da aposentadoria, pois, ao apresentarem maior controle sobre suas carreiras, eram capazes de reduzir as horas de trabalho, tendo assim uma transição gradual. Platman (2003) considera que, para autônomos, a aposentadoria não é percebida como um período de inatividade e improdutivo; pelo contrário, pode ser uma fase de maior autorregulação sobre o que fazer e quando fazer. Nesse sentido, ressalta-se que a possibilidade de adotar uma aposentadoria parcial, baseada na redução das horas trabalhadas, torna-se uma das estratégias efetivamente aplicadas pelos profissionais autônomos (Kim \& DeVaney, 2005). A tendência de escolher uma aposentadoria parcial pode ser vista como uma escolha racional dos autônomos, já que a flexibilidade para estabelecer horários e tarefas possibilita que eles não mante- 
nham a mesma carga de trabalho antes adotada. Nesse ponto, cabe ressaltar que, mesmo que trabalhadores empregados, independente do tipo de ocupação, muitas vezes desejem uma aposentadoria parcial, nem todos podem consegui-la devido às características dos seus trabalhos. Ekerdt, Deviney e Kosloski (1996) afirmam que os autônomos tendem a investir pessoalmente no seu trabalho, levando a um alto custo para a sua identidade se ocorrer uma saída abrupta e completa do trabalho em função da aposentadoria. Dessa forma, tendem a planejar uma redução do volume de trabalho, porém são contrários a uma troca de atividade. Não há um desejo de mudar de carreira a partir (ou em função) da transição para a aposentadoria. Assim, a saída de autônomos do mercado de trabalho associase mais fortemente à existência de limitações físicas para o efetivo exercício de suas atividades ocupacionais (Parry \& Taylor, 2007; Quinn, 1980).

De forma geral, pode-se concluir que profissionais autônomos possuem a tendência de continuarem trabalhando com a chegada da aposentadoria. Mesmo que aparentem indecisão sobre esta etapa de carreira, geralmente planejam uma redução da sua carga horária de trabalho, caracterizando assim uma situação de aposentadoria parcial. A aposentadoria parece não modificar de forma drástica a configuração de carreira dos autônomos, visto que a flexibilidade e a ausência de imposições sociais (como uma aposentadoria compulsória) proporcionam maior controle sobre uma transição gradual. Entretanto, alguns pontos ainda permanecem em aberto ao se pensar na experiência de aposentadoria em autônomos. Platman (2003) afirma que há poucas pesquisas sobre profissionais autônomos mais velhos. Pode-se acrescentar que estudos sobre como o trabalhador autônomo vivencia a sua aposentadoria e como esta se relaciona com os outros contextos de sua vida ainda são incipientes. Dessa forma, o objetivo desse estudo foi descrever e compreender a experiência de aposentadoria em profissionais autônomos a partir da perspectiva dos próprios aposentados. Ressalta-se que este estudo, de caráter qualitativo, se propõe a investigar a temática em uma perspectiva exploratória e descritiva.

\section{MÉTODO}

\section{Participantes}

Participaram desse estudo dez profissionais autônomos aposentados, com idades entre 60 e 91 anos, variando no grau de escolaridade de ensino médio incompleto a ensino superior completo, sendo que nenhum parou de trabalhar logo que passou a receber o benefício da aposentadoria. Para participação no estudo, os seguintes critérios de inclusão foram adotados: 1) estar financeiramente aposentado, ou seja, receber o benefício previdenciário da aposentadoria e 2) identificar-se, via autorrelato, como um profissional autônomo. A Tabela 1 apresenta as características dos participantes quanto a sexo, idade, atividade profissional, tempo como aposentado/a e se estava trabalhando no momento da entrevista.

Tabela 1

Participantes do Estudo

\begin{tabular}{ccccc}
\hline Sexo & Idade & Atividade profissional & Tempo $^{*}$ & Trabalhando \\
\hline Fem & 60 & Empresária & 1 & Sim \\
Masc & 74 & Com. Exterior & 4 & Sim \\
Fem & 64 & Psicóloga & 5 & Sim \\
Fem & 78 & Costureira & 5 & Não \\
Fem & 91 & Doceira & 5 & Não \\
Fem & 63 & Médica & 10 & Sim \\
Masc & 65 & Quiroprata & 11 & Não \\
Fem & 66 & Farmacêutica & 16 & Não \\
Fem & 80 & Costureira & 17 & Não \\
Fem & 80 & Farmacêutica & 25 & \\
\hline
\end{tabular}

* Tempo como aposentado(a), em anos. 


\section{Instrumento}

Utilizou-se uma entrevista semiestruturada a fim de investigar a experiência de aposentadoria em profissionais autônomos. A entrevista foi organizada em torno dos seguintes tópicos: opção pelo trabalho autônomo, trajetória de trabalho, decisão sobre aposentadoria, significado da aposentadoria, vida como aposentado e perspectivas para o futuro.

\section{Procedimentos}

Os participantes foram contatados a partir de indicações da rede social dos pesquisadores e também pelos próprios participantes, à medida que a coleta de dados foi iniciada. Além disso, a pesquisa foi divulgada em um projeto voltado ao público da terceira idade, sendo convidados a participar todos os que se percebiam como autônomos aposentados. Aqueles que mostraram disponibilidade de participar da pesquisa preencheram uma ficha de interesse, e depois foram contatados via telefone. As entrevistas foram realizadas na residência do participante ou na universidade, conforme conveniência. A duração das entrevistas variou entre 40 e 90 minutos, sendo todas gravadas em áudio e posteriormente transcritas para análise. A pesquisa foi previamente aprovada por um Comitê de Ética da instituição de vínculo dos pesquisadores, e os entrevistados assinaram um Termo de Consentimento Livre e Esclarecido antes da participação.

\section{Análise dos dados}

O processo de análise de dados adotado nesse estudo seguiu a orientação da fenomenologia empírica, conforme proposto por Giorgi (1997), englobando as etapas de redução, descrição e interpretação. Inicialmente a análise consistiu na leitura de toda a descrição do material coletado, a fim de se compreender o sentido geral do todo. Após esse momento, foram identificadas passagens revelatórias nas entrevistas focadas na experiência de ser um profissional autônomo aposentado. Para isso, foi necessário suspender os conhecimentos teóricos anteriores, assim como as expectativas pessoais sobre o fenômeno, a fim de acessá-lo de forma genuína à consciência (Giorgi, 2006). Buscou-se adotar uma atitude de abertura ao fenômeno estudado a fim de apresentar o fenômeno conforme vivido pelo sujeito de um modo direto e não avaliativo.

Posteriormente, as passagens revelatórias foram agrupadas em categorias descritivas, compondo a etapa de descrição fenomenológica. A seguir as categorias foram reduzidas, identificando temas que sinte- tizam a estrutura da experiência (redução fenomenológica). Através da variação imaginativa livre, tornou-se possível desvelar características essenciais do fenômeno, sintetizando a experiência em sua estrutura básica (Giorgi, 2006). Por fim, a interpretação fenomenológica consistiu na compreensão dessa experiência buscando uma articulação entre os dados e a literatura.

\section{RESULTADOS}

Dada a extensão do material correspondente à descrição fenomenológica, optou-se, para esse estudo, pela apresentação dos resultados a partir da etapa reflexiva de redução, visto que esta organiza e integra a etapa de descrição. Sendo assim, na redução buscou-se organizar os elementos da descrição em dimensões mais amplas, identificando temas que compõem a estrutura do fenômeno estudado. Cinco temas foram identificados e são apresentados a seguir: 1) sendo autônomo; 2) aposentadoria; 3) trabalho; 4) família; e 5) temporalidade.

\section{Sendo autônomo}

O processo de entrada no mercado autônomo caracterizou-se pela influência de diferentes fatores que fizeram com que os participantes optassem por esse tipo de trajetória. Em um nível individual, pode-se citar a avaliação de interesses e valores profissionais que, desde o início do exercício das atividades laborais, moldaram as escolhas feitas. Por exemplo, um desejo de atuar como profissional liberal na área de psicologia clínica ou uma posição crítica frente à influência do poder público nos diversos ramos ocupacionais, levando assim à escolha de uma carreira que sofresse menos influência direta da gerência do Estado. Porém, além dessa motivação individual para o trabalho autônomo, também foi identificada uma motivação mercadológica, ou seja, a necessidade de conseguir um trabalho, independente de qual fosse. Assim, ser um autônomo constituiu-se como um ajuste às dificuldades encontradas para se inserir no mercado assalariado. A importância do contexto mercadológico aumenta quando a profissão escolhida apresenta áreas de atuação restritas (em termos de empregos formais), que acabam encaminhando o profissional a uma carreira autônoma, mesmo que este não fosse seu desejo inicial. De fato, no campo de estudos sobre profissionais autônomos, identificam-se dois caminhos de entrada no mercado de trabalho: o mercadológico (o mercado leva o individuo a ser autônomo, sendo esta a melhor ou única opção possível, mas não necessaria- 
mente a de maior interesse do trabalhador) e o empreendedor (o projeto de carreira do indivíduo baseia-se na sua escolha por ser autônomo) (Hatala, 2005).

Entretanto, as justificativas por ser autônomo não se encerram nessas duas perspectivas. Uma questão de gênero também foi apontada como importante justificativa para a trajetória escolhida. Exclusivamente para as mulheres, outros tipos de carreiras foram desaconselhados e até proibidos por pais e cônjuges que julgavam que suas filhas e esposas não deveriam estudar ou trabalhar fora de casa. Assim, o que restou foi a inserção em tarefas tipicamente femininas, como costurar e cozinhar. Por vezes, a abertura de algum tipo de negócio possibilitou que estas mulheres trabalhassem conjuntamente com seus esposos; todavia, o cônjuge ainda permaneceu como a figura responsável pelas principais decisões sobre o empreendimento. De modo geral, questões de gênero tendem a influenciar a forma como se experencia a aposentadoria, sendo que as mulheres podem vivenciar maior heterogeneidade nessa experiência, se comparadas aos homens, visto que estes possuem expectativas sociais de carreira mais bem definidas (Moen, 1996).

Durante o exercício da profissão, características do trabalho autônomo mostraram-se importantes na modulação da forma como o trabalho se ajusta aos demais contextos da vida dos participantes. Nesse sentido, a flexibilidade de organizar o trabalho segundo interesses pessoais, por exemplo, para aumentar o seu nível de produtividade, e familiares, como conjugar o papel de trabalhador com os papéis de cônjuge e cuidador, possibilitou aos participantes a construção de um ambiente condizente com suas aspirações de vida. A tomada de controle pela própria carreira e a flexibilidade em manejar quais, quando e como as atividades serão realizadas têm sido apontadas como algumas das principais motivações de entrada e de permanência no trabalho autônomo (Peel \& Inkson, 2004).

\section{Aposentadoria}

A aposentadoria foi percebida basicamente através de sua dimensão econômica, isto é, como o recebimento de um benefício social. Com isso, não foram percebidas mudanças emocionais significativas a partir do momento em que a aposentadoria ocorreu, pois os participantes propuseram-se a continuar trabalhando, independente do aumento do rendimento mensal propiciado pelo benefício. Ressalta-se que nenhum participante parou de trabalhar em função do recebimento da aposentadoria. $\mathrm{O}$ desejo de permanecer trabalhando vincula-se ao objetivo de ainda sentir-se produtivo e útil para a sociedade. Nesse sentido, os aposentados que ficam em casa são vistos como inativos sociais. De acordo com Duarte e Melo-Silva (2009), a perspectiva de não mais trabalhar pode ser acompanhada de sentimentos negativos de inatividade, de fim da trajetória profissional e de perda das capacidades funcionais. Esse tipo de crença relacionado à aposentadoria parece dificultar a identificação do indivíduo com esse grupo social, causando insegurança e, por vezes, negação frente a essa nova condição de reconhecimento social.

Entretanto, a insegurança já referida parece conviver com a percepção de vantagens do pertencimento a um novo grupo social. Além de, por exemplo, poder usufruir de descontos em eventos culturais, o simples fato de estar em um grupo socialmente nomeado - os aposentados - parece afastar a sensação de estar anteriormente em um limbo de reconhecimento social. Por limbo social entende-se uma posição social (papel) na qual o indivíduo não se considera nem trabalhador pleno nem ainda aposentado, sendo associada à ideia de que, nos anos anteriores à aposentadoria, não se é adolescente nem ainda aposentado. Com o recebimento do benefício, é possível então se descrever como pertencente a uma categoria e, consequentemente, ser reconhecido por outros como integrante de um grupo maior.

\section{Trabalho}

O trabalho foi percebido como fonte de realização tanto financeira quanto pessoal. Independente dos motivos de entrada na profissão, os participantes relataram trajetórias de carreira satisfatórias. O desejo de continuar trabalhando justificou-se pela avaliação de que o trabalho é um importante contexto de convívio social e de trocas sociais que promove reconhecimento e valorização do que se produz. Ao lado desse desejo está a percepção de que, por vezes, é ou será necessário diminuir as atividades laborais. Os motivos associados a isto podem ser organizados em dois grandes fatores: externo e interno. $\mathrm{O}$ fator externo caracteriza-se pela presença de elementos não associados diretamente ao indivíduo, mas que colaboram para a decisão de continuar (ou não) o ritmo de trabalho, por exemplo, questões mercadológicas da profissão. Já o fator interno relaciona-se mais especificamente com aspectos individuais, como a condição física e mental percebida. O momento de parar de trabalhar parece muito dependente da avaliação do quanto ainda se é saudável física e mentalmente para o exercício satisfatório da profissão. 
Aproveitando-se das vantagens percebidas do trabalho autônomo, os participantes adotam estratégias de diminuição do ritmo de trabalho, evitando assim uma parada abrupta. Disponibilizar alguns turnos semanais para a realização de tarefas pessoais, limitar o horário de trabalho e acomodar diferentes períodos de férias ao longo do ano são alguns exemplos citados pelos participantes a fim de balancear seus interesses pessoais às demandas do trabalho. Ser autônomo parece possibilitar, através da flexibilidade percebida, a composição de diferentes cenários nesse momento de transição.

Para aqueles participantes que pararam de trabalhar, foi possível perceber três modalidades de reações: a indiferença, a avaliação positiva e a insatisfação gerada pela redução da renda. Na situação de indiferença, o fato de deixar de trabalhar foi percebido como uma transição sem grandes impactos emocionais. Para outros, não estar mais trabalhando possibilitou o envolvimento com outras atividades e outros papéis, o que foi visto como positivo. Por fim, mesmo com o recebimento do benefício, parar de trabalhar implicou também a perda da renda proveniente da ocupação anterior. Isto significou, para alguns participantes, uma diminuição da independência financeira, gerando um sentimento de insatisfação.

\section{Família}

Um dos temas recorrentes nas falas dos participantes foi o contexto da família. O reconhecimento de que os filhos estão crescidos e estabelecidos profissionalmente levou a uma maior liberdade para a tomada de decisões de carreira. Não havendo mais a necessidade de se preocupar com a dependência dos filhos frente ao seu trabalho, os pais, agora aposentados, puderam definir sua trajetória futura com base em seus interesses pessoais. Por outro lado, a diminuição da preocupação com os filhos ou mesmo a sua saída de casa leva a uma reconfiguração da relação do casal. Dessa forma, a relação do casal passa a demandar novas aprendizagens de como agir frente à crise do ninho vazio. Além disso, o cônjuge mostrou-se figura essencial na compreensão de como o autônomo vincula-se ao seu trabalho. Por vezes, o cônjuge é a referência do contexto de trabalho e de vida do participante, sendo que a sua presença (ou ausência) bem como suas opiniões podem moldar a trajetória de carreira escolhida.

\section{Temporalidade}

Envelhecimento e aposentadoria apareceram relacionados nas falas dos entrevistados, uma vez que a percepção dos efeitos da passagem do tempo sobre o próprio corpo trouxe à consciência a realidade da velhice e dos limites fisiológicos consequentes à idade. Questionamentos sobre futuro e finitude colocaram-se como pauta nesse novo contexto de vida, fazendo que as metas se tornassem focadas no curto prazo. Os objetivos de vida tornaram-se os pequenos prazeres do cotidiano, como aproveitar a companhia de amigos e familiares. A perspectiva temporal de futuro passou a ser balizada pelos eventos do dia-a-dia, isto é, o planejamento foi visto mais como uma reação às ocorrências do cotidiano do que uma resposta proativa e previamente preparada (Denton et al., 2004).

Já quanto ao que foi feito no passado com o intuito de prepararem-se para a aposentadoria, os entrevistados relataram basicamente uma preparação financeira que consistiu principalmente na contribuição à previdência pública. Ressalta-se, porém, que a falta de controle sobre o montante efetivamente contribuído e a ausência de outras economias acarretaram problemas no momento de avaliar a situação financeira no momento da aposentadoria. Existe a percepção de que algo poderia ter sido feito de diferente com relação a isso, porém já não havia mais tempo de adotar outra estratégia de preparação financeira.

Como resultado do processo de redução, é possível então propor uma descrição sintética da experiência de aposentadoria em profissionais autônomos:

A experiência de aposentadoria em profissionais autônomos caracteriza-se por uma conjugação de diferentes aspectos: o ser autônomo, o benefício da aposentadoria, a relação com o trabalho e a família e a temporalidade. A forma de inserção no mercado autônomo, assim como as características específicas desse tipo de atividade, parece indicar a estrutura na qual o indivíduo constrói sua trajetória de carreira. Mesmo sendo entendida basicamente como o recebimento de um benefício social, a aposentadoria é marcada pelo pertencimento a um grupo socialmente reconhecido, que pode carregar marcas de um estereótipo social de improdutividade. $O$ desejo de continuar trabalhando é atravessado pela percepção de que um dia as atividades serão diminuídas, principalmente em função da condição física $e$ mental percebida. O contexto familiar ganha saliência na experiência vivida, já que filhos e cônjuges são figuras essenciais para as mudanças envolvidas na aposentadoria. A aposentadoria carrega também a marca da percepção da passagem do tempo, do envelhecimento, da avaliação dos planos que foram feitos e da projeção de planos a curto prazo. 


\section{DISCUSSÃO}

\section{Interpretação fenomenológica}

A redução fenomenológica ressaltou que a experiência de aposentadoria em profissionais autônomos caracteriza-se pelo rearranjo de diferentes papéis sociais e contextos de vida. O papel de trabalhador apresenta uma relação dinâmica com outros papéis de vida do sujeito, como o papel de cônjuge, de pai/mãe e mesmo de aposentado. Na interpretação fenomenológica, busca-se avançar na compreensão do fenômeno, procurando articular os elementos destacados na redução, a fim de desvelar possíveis sentidos da experiência (Giorgi, 1997). Cabe salientar que a interpretação não pretende constituir-se em uma conclusão definitiva sobre o fenômeno em questão, mas sim em um alargamento das possibilidades de compreensão do mesmo, sempre aberta a novas leituras.

Inicialmente, é possível perceber que as peculiaridades de carreira dos profissionais autônomos se refletem na forma como estes vivenciam a aposentadoria. Basicamente, os autônomos organizam seu trabalho em um ambiente flexível, com regras de funcionamento que visam adequar-se com suas necessidades pessoais e profissionais. Essa maior liberdade na forma de gerenciar a própria carreira torna a transição e a vivência da aposentadoria mais dinâmica e pouco influenciada por marcadores sociais, ao contrário dos trabalhadores assalariados que tendem a ter um ciclo de vida mais linear - educação, trabalho e aposentadoria (Parry \& Taylor, 2007). Os autônomos apresentam um controle maior quanto à transição para a aposentadoria por não sofrerem tanta influência externa sobre como, quando e se irão parar de trabalhar. A postura autônoma e empreendedora aplicada ao trabalho tende a ser a mesma no momento em que pensam a aposentadoria.

É a partir de um contexto de trabalho flexível, almejado e satisfatório que os autônomos vislumbram a aposentadoria. Em um primeiro momento, a aposentadoria é percebida apenas como o recebimento de um benefício, sendo rejeitada a idéia de um afastamento das atividades laborais. Na trajetória de carreira dos autônomos não há a previsão de uma aposentadoria compulsória ou ditada por regras externas, o que acarreta uma dificuldade, ou mesmo uma evitação, em se identificar como aposentado. Entretanto, no contínuo entre permanecer trabalhando normalmente após a aposentadoria e parar completamente as tarefas ocu- pacionais, pode-se apontar como ponto de transição a diminuição das atividades de trabalho. Vista como uma aposentadoria parcial, a adoção dessa estratégia possibilita que os trabalhadores façam uma passagem gradual do trabalho para o não trabalho. Para os autônomos, a flexibilidade do gerenciamento de horários torna a escolha por uma aposentadoria parcial quase como uma decisão natural e esperada (Kim \& Devaney, 2005). O desengajamento do papel de trabalhador não precisa ocorrer abruptamente, possibilitando que o sujeito controle a melhor forma e o melhor momento de parar de trabalhar. A saída total do mercado de trabalho acaba sendo dependente de uma avaliação das condições de saúde para o efetivo exercício da profissão. Enquanto o corpo e a mente possibilitarem a atuação profissional, os autônomos tendem a se manter comprometidos e engajados com seu papel de trabalhador.

Dessa forma, pode-se perceber que, para esses profissionais, o fato de estar aposentado não significa necessariamente um desligamento do trabalho, mas sim uma transformação do papel de trabalhador. O conceito de desengajamento, visto como o desligamento natural das atividades laborais em função da aposentadoria começa a ser questionado, já que ser aposentado não significa necessariamente a perda do papel de trabalhador (Chen, 2011). A rotina e as atividades de trabalho podem permanecer iguais, porém a aposentadoria coloca-se agora como algo a ser considerado pelo sujeito no momento de projetar os próximos passos de sua carreira. A perspectiva construtivista de carreira (entendida como uma expansão teórica da abordagem life-span, life-space) enfatiza o caráter individual e o sentido que o sujeito atribui a sua trajetória de carreira (Savickas, 2002). Frente à narrativa individual de carreira, as grandes expectativas sociais sobre transições ocupacionais acabam diminuindo de importância, pois o que precisa ser considerado é a carreira que foi construída por aquele indivíduo, isto é, sua carreira subjetiva. Aliado a isso, a sociedade atual não se caracteriza mais pela sua previsibilidade e estabilidade de anos atrás, levando ao questionamento sobre se ainda é viável e funcional demarcar a trajetória de carreira do sujeito a partir de tarefas sociais esperadas (Savickas et al., 2009).

Neste ponto, ressalta-se que para os autônomos o recebimento do benefício da aposentadoria não adquire a função de marcador social para uma possível saída do mercado de trabalho, uma vez que se caracteriza apenas como um ponto de certa forma arbitrário na 
biografia ocupacional do trabalhador (Parry \& Taylor, 2007). O parâmetro adotado para não mais desempenhar o papel de trabalhador torna-se muito mais biológico (relacionado à saúde) do que social e, por isso, difícil de localizar temporalmente. Sabe-se que, com o passar dos anos, há um declínio natural das condições de saúde; entretanto, não é possível precisar o momento específico em que esse declínio impossibilitará o sujeito de exercer suas atividades laborais. Pode-se inferir que a referência temporal dos autônomos baseia-se em um marcador que é biológico e pouco preciso (o envelhecer), dificultando que consigam planejar a sua vida como aposentados. A antecipação da saída do mercado de trabalho parece ser mais fácil para trabalhadores assalariados, pois possuem rendimentos mais bem definidos e um contexto que, muitas vezes, indica idades-limite para a sua aposentadoria (Cobb-Clark \& Stillman, 2009).

Além da dimensão longitudinal, os diferentes contextos/espaços de vida do trabalhador autônomo mostraram-se fatores importantes de serem levados em consideração na descrição da estrutura de sua experiência de aposentadoria. A compreensão da aposentadoria em autônomos torna-se incompleta se for deslocada da influência dos outros papéis sociais do indivíduo. Neste ponto, salienta-se a dinâmica envolvida entre os papéis de trabalhador, de cônjuge e de cuidador. A influência do cônjuge e de outros familiares mostrou-se importante quanto à forma de inserção no mercado de trabalho, principalmente no caso das mulheres, pela restrição ao desempenho de certas tarefas tidas como não apropriadas ao seu gênero. A discriminação de gênero tem sido apontada como uma das justificativas possíveis para a entrada de mulheres no mercado de trabalho autônomo, acarretando que abdiquem de seus planos profissionais para realizarem atividades que não eram desejadas (Rosti \& Chelli, 2005). Neste caso, as trajetórias de carreiras dessas mulheres foram moldadas pelas escolhas de terceiros (especialmente pais e maridos), o que pode influenciar na forma como se apropriam e se relacionam com o trabalho.

Para os entrevistados, decisões importantes acerca da aposentadoria também sofreram influência de figuras como esposo/a e filhos/as. Por exemplo, a decisão de parar de trabalhar, além de depender de uma avaliação das condições de saúde, é tomada de acordo com a percepção de independência pessoal e financeira dos filhos. Já especificamente sobre a relação do casal, é interessante ressaltar que o cônjuge influenciou de maneira marcante as decisões sobre aposentadoria, como parar, não parar de trabalhar ou diminuir as atividades. Mesmo que os autônomos apresentem um controle maior sobre suas carreiras, isto não significa que tomem decisões isoladamente. De maneira geral, casais que são autônomos tendem a preferir uma aposentadoria tardia; entretanto, esta decisão tende a ser construída conjuntamente pelo casal, indicando a busca de um equilíbrio não apenas entre o autônomo e seu trabalho, mas sim entre o autônomo, seu trabalho e sua família (Pienta \& Hayward, 2002).

Ao se investigar o fenômeno da aposentadoria em profissionais autônomos, deve-se considerar uma variabilidade de contextos que, de forma conjunta, constroem a maneira como o sujeito vive a sua experiência. A aposentadoria, enquanto transformação do papel de trabalhador, modifica a dinâmica de outros papéis desempenhados pelo sujeito. Nesse sentido, aposentar-se promove dois movimentos importantes na estrutura de vida do trabalhador autônomo. Em primeiro lugar, pode-se citar uma transformação na dinâmica interna dos papéis desempenhados pelo indivíduo, isto é, uma mudança na ecologia interna dos papéis. A aposentadoria possibilita que o autônomo diminua suas atividades laborais, o que pode levá-lo a engajar-se em atividades de lazer e/ou serviços comunitários, a disponibilizar mais tempo ao cuidado dos netos, etc. A mudança na forma de interagir com outros papéis sociais, provocando por vezes um reengajamento com papéis que eram antes pouco salientes, caracteriza-se como uma das tarefas importantes a serem cumpridas pelos aposentados a fim de manterem uma postura pró-ativa para a continuidade de sua trajetória de carreira (Chen, 2011). De maneira complementar, em segundo lugar, a aposentadoria acarreta uma modificação também na dinâmica dos papéis entre os indivíduos, ou seja, uma mudança na ecologia familiar dos papéis. A transformação no papel de trabalhador repercute em uma nova dinâmica para o casal, os filhos e os netos. Filhos crescidos e independentes proporcionam que o casal se tome novamente como foco de atenção e este momento tende a coincidir com a chegada da aposentadoria. Novos investimentos de tempo e comprometimento com a relação podem ser feitos, visto que não há mais a necessidade de um cuidado maior com os filhos e há um aporte financeiro estável proveniente do recebimento do benefício. Ao mesmo tempo em que se pode afirmar que não existe uma relação direta entre crise do ninho vazio e aposentadoria, por outro lado, não se pode negar a simultaneidade de ambos os fenômenos em muitas situações. Nesse estudo, visto que não foi um 
foco inicial da pesquisa, não foi possível aprofundar e compreender com melhor clareza como a aposentadoria interage com a dinâmica do ciclo familiar e conjugal.

De forma geral, pode-se afirmar que o aposentar-se do profissional autônomo não é o desligamento do papel de trabalhador, mas sim uma reorganização na forma de se relacionar com o trabalho, marcada pelo envelhecimento. Entre a aposentadoria (recebimento de benefício) e o desengajamento do papel de trabalho há um hiato que é preenchido de maneira idiossincrática por cada autônomo. A maneira como o autônomo construirá essa transição dependerá tanto do seu papel de trabalhador quanto dos seus outros papéis de vida.

Por fim, torna-se necessário considerar algumas questões referentes a este estudo empírico. Seguindo uma lógica qualitativa, descritiva e exploratória, o objetivo desse trabalho foi apontar possibilidades de compreensão da experiência de aposentadoria em autônomos, não possuindo a intenção de apresentar resultados generalizáveis a qualquer tipo de público ou de contexto. Além disso, apesar de ser orientado por uma abordagem de desenvolvimento de carreira, esse estudo foi realizado de forma transversal, o que limitou a análise a uma visão retrospectiva acerca de como as transições de carreira se constroem ao longo do tempo. Ressalta-se também a heterogeneidade entre os participantes, caracterizados por diferentes tipos de escolaridade e ocupação. Nesse sentido, buscou-se valorizar as diferenças entre as experiências a fim de descrever uma maior riqueza de possibilidades. Sugere-se que novas pesquisas sejam realizadas buscando selecionar atividades autônomas específicas, a fim de investigar se há peculiaridades em cada subgrupo profissional. Além do mais, pesquisas longitudinais podem mapear como se constrói a experiência de aposentadoria ao longo do tempo, indicando as transformações ocorridas entre os papéis sociais e como o sujeito atribui significado a estas mudanças.

\section{REFERÊNCIAS}

Chen, C. P. (2011). Life-career re-engagement: a new conceptual framework for counseling people in retirement transition - part I. Australian Journal of Career Development, 20(2), 25-31. doi: 10.1177/103841621102000204

Cobb-Clark, D. A., \& Stillman, S. (2009). The retirement expectations of middle-aged Australians. The Economic Record, 85(269), 146-163. doi: 10.1111/j.1475-4932.2009.00543.x

Denton, M. A., Kemp, C. L., French, S., Gafni, A., Joshi, A., Rosenthal, C. J., \& Davies, S. (2004). Reflexive planning for later life. Canadian Journal on Aging, 23(supp.), 71-82.
DeVaney, S. A., \& Kim, H. (2003). Older self-employed workers and planning for the future. Journal of Consumer Affairs, 37(1), 123-142. doi: 10.1111/j.1745-6606.2003.tb00443.x

Duarte, C. V., \& Melo-Silva, L. L. (2009). Expectativas diante da aposentadoria: um estudo de acompanhamento em momento de transição. Revista Brasileira de Orientação Profissional, 10(1), 45-54.

Earle, J. S., \& Sakova, Z. (2000). Business start-ups or disguised unemployment? Evidence on the character of self-employment from the transition economies. Labour economics, 7, 575-601.

Ekerdt, D. J., DeViney, S., \& Kosloski, K. (1996). Profiling plans for retirement. Journal of Gerontology: Social Sciences, $51 B(3), 140-149$.

Ekerdt, D. J., Hackney, J., Kosloski, K., \& DeViney, S. (2001). Eddies in the stream: the prevalence of uncertain plans for retirement. Journal of Gerontology: Social Sciences, 56B(3), 162-170.

Ekerdt, D. J., Kosloski, K., \& DeViney, S. (2000). The normative anticipation of retirement by older workers. Research on Aging, 22(1), 3-22. doi: 10.1177/0164027500221001

Giorgi, A. (1997). The theory, practice, and evaluation of the phenomenological method as a qualitative research procedure. Journal of Phenomenological Psychology, 28(2), 235-260. doi: $10.1163 / 156916297 \times 00103$

Giorgi, A. (2006). Difficulties encountered in the application of the phenomenological method in the social sciences. Análise Psicológica, 3(24), 353-361.

Hatala, J. (2005). Identifying barriers to self-employment: the development and validation of the barriers to entrepreneurship success tool. Performance Improvement Quarterly, 18(4), 5070. doi: 10.1111/j.1937-8327.2005.tb00350.x

Kim, H., \& DeVaney, S. A. (2005). The selection of partial or full retirement by older workers. Journal of family and Economic Issues, 26(3), 371-394. doi: 10.1007/s10834-005-5903-8

Kim, J. E., \& Moen, P. (2002). Retirement transitions, gender, and psychological well-being: a life-course, ecological model. Journal of Gerontology: Psychological Sciences, 57B(3), 212222.

Le, A. T. (1999). Empirical studies of self-employment. Journal of Economic Surveys, 13(4), 381-416. doi: 10.1111/14676419.00088

Moen, P. (1996). A life course perspective on retirement, gender, and well-being. Journal of Occupational Health Psychology, 1(2), 131-144. doi: 10.1037/1076-8998.1.2.131

Mourão, L., \& Pantoja, M. J. (2010). O psicólogo autônomo e voluntário: contextos, locais e condições de trabalho. In A. V. B. Bastos \& S. M. G. Gondim (Orgs.). O trabalho do psicólogo no Brasil (pp. 151-173). Porto Alegre: Artmed.

Parry, J., \& Taylor, R. F. (2007). Orientation, opportunity and autonomy: why people work after state pension age in three areas of England. Aging \& Society, 27, 579-598. doi: 10.1017/S0144686X0700606X 
Peel, S., \& Inkson, K. (2004). Contracting and careers: choosing between self and organizational employment. Career Development International, 9(6), 542-558.

Pienta, A. M., \& Hayward, M. D. (2002). Who expects to continue working after age 62 ? The retirement plans of couples. Journal of Gerontology: Social Sciences, 57B(4), 199-208.

Platman, K. (2003). The self-designed career in later life: a study of older portfolio workers in the United Kingdom. Ageing \& Society, 23, 281-302. doi: 10.1017/S0144686X03001168

Quinn, J. F. (1980). Labor-force participation patterns of older self-employed workers. Social Security Bulletin, 43(4), 17-28.

Rosti, L., \& Chelli, F. (2005). Gender discrimination, entrepreneurial talent and self-employment. Small Business Economics, $24,131-142$.

Savickas, M. L, Nota, L., Rossier, J., Dauwalder, J., Duarte, M. E., Guichard, J., ... van Vien, A.E.M. (2009). Life designing: a paradigm for career construction in the 21st century. Journal of Vocational Behavior, 75, 239-250.

Savickas, M. L. (2002). Career Construction: A developmental theory of vocational behavior. In D. Brown \& Ass. (Orgs.), Career Choice and Development (4th Ed.; pp.149-205). San Francisco: Jossey-Bass.
Shultz, K. S., \& Wang, M. (2011). Psychological perspectives on the changing nature of retirement. American Psychologist, 66(3), 170-179.

Soidre, T. (2005). Retirement-age preferences of women and men aged 55-64 years in Sweden. Ageing \& Society, 25, 943-963. doi: 10.1017/S0144686X05004216

Super, D. E., Savickas, M. L., \& Super, C. M. (1996). The lifespan, life-space approach to careers. In D. Brown \& L. Brooks (Orgs.), Career choice and development ( ${ }^{\text {rd }}$ ed., pp. 121-178). San Francisco: Jossey-Bass.

Templer, A., Armstrong-Stassen, M., \& Cattaneo, J. (2010). Antecedents of older workers' motives for continuing to work. Career Development International, 15(5), 479-500.

Recebido em 04/08/2012 Primeira Decisão Editorial em 31/12/2012 Aceito em 06/03/2013 